\title{
The Stigma of Epilepsy among Outpatients in a Tertiary Hospital in South-East Nigeria
}

\author{
Justin U. Achor'1*, Birinus A. Ezeala-Adikaibe², Okwudili N. Obayi³, Chinwe F. S. Ezeruigbo, \\ Oluchi S. Ekenze ${ }^{2}$, Obinna D. Onodugo²
}

${ }^{1}$ Federal Neuropsychiatric Hospital, Enugu, New Haven, Nigeria

${ }^{2}$ Department of Medicine, University of Nigeria Teaching Hospital, Ituku/Ozalla, Nigeria

${ }^{3}$ Department of Psychological Medicine, Ebonyi State University, Abakaliki, Nigeria

${ }^{4}$ Department of Nursing Sciences, Faculty of Health Science, Ebonyi State University, Abakaliki, Nigeria

Email: *juachor@yahoo.com, nigeriaepilepsy@hotmail.com, okwudiliobayi@yahoo.com, chinweezeruigbo@yahoo.com,

ekenze2001@yahoo.com, obinnaonodugo@yahoo.com

How to cite this paper: Achor, J.U., Ezeala-Adikaibe, B.A., Obayi, O.N., Ezeruigbo, C.F.S., Ekenze, O.S. and Onodugo, O.D. (2017) The Stigma of Epilepsy among Outpatients in a Tertiary Hospital in SouthEast Nigeria. Open Journal of Psychiatry, 7, 344-364.

https://doi.org/10.4236/ojpsych.2017.74029

Received: August 14, 2017

Accepted: September 18, 2017

Published: September 21, 2017

Copyright $\odot 2017$ by authors and Scientific Research Publishing Inc. This work is licensed under the Creative Commons Attribution International License (CC BY 4.0).

http://creativecommons.org/licenses/by/4.0/

\begin{abstract}
Background: The stigma of epilepsy is pervasive in developing country contexts and negatively affects the psychological and social wellbeing of its sufferers. The experience of stigma varies across settings and probably relate to disease severity and social characteristics. This study sought to describe the extent and correlates of perceived and enacted stigma among outpatients with epilepsy. Methods: The participants were consecutively presenting epilepsy outpatients in a tertiary facility that attended clinic regularly and had no overt medical or psychiatric co-morbidities. The patients were interviewed with a semi-structured questionnaire. Results: There were 93 participants with a mean age of $30.2 \pm 10.3$ years and $57.0 \%$ were males. The experience of stigma was reported by $46.2 \%$ and $67.7 \%$ of the participants for perceived and enacted stigma, respectively. Over one-third of the patients had suffered burns or a similar injury in the past. The correlates of perceived stigma were rural residence, lower levels of education, and longer duration of illness. Gender, age and frequency of seizures were not statistically significant determinants. The correlates of enacted stigma were being single, older age, rural residence, and longer duration of epilepsy. A past history of burns and disclosure of epilepsy to individuals outside the family added to the likelihood of experiencing stigma. Conclusion: The burden of epilepsy related social stigma is high in Nigeria. Cultural stereotypes and misconception add to this. There is need for appropriate culture-congruent educational interventions to provide the right information about epilepsy and debunk the misconceptions and myths associated with the condition. This will need to be coupled with astute clinical management of cases and active case finding. Both qualitative and longitudinal quantitative studies would be required to deepen our understanding of the
\end{abstract}


lived reality of grappling with stigma in our setting.

\section{Keywords}

Epilepsy Stigma, Perceived/Enacted Nigeria

\section{Introduction}

Epilepsy causes significant and worrisome life disruption, morbidity and uncertainty among its sufferers and these are related to the nature of the neurological condition [1] [2]. It is associated with debilitating social and psychological impacts, which also contribute to the devastation of the lives and wellbeing of the affected individuals. There is a high level of stigmatization of epileptic patients [3] to which is contributed by prevalent cross-cutting myths and misconceptions surrounding the disease in virtually all societies. For instance, in Africa, epilepsy is considered to be a form of severe psychiatric illness that arises from a "curse of the gods" or demonic possession [4]. Individuals with this condition are intensely avoided, feared and/or rejected on account of these considerations. The awareness of the impact of the psychological problems associated with epilepsy is important in the treatment of epileptic patients. Such psychological and social problems can impact negatively on the mental health and wellbeing of the individuals as well as seizure control.

It has been surmised that the psychosocial limitations that accompany epilepsy, especially in relation to interpersonal relationships and employment are more likely to result from the stigma that is associated with the disorder than from the epileptic seizures per se [5] [6]. Stigma refers to a personal characteristic that marks a person as being different, and possessing a tainted, discrediting identity [7]. This individual is considered to be blemished and therefore a target for social discrimination. Misinformation and negative attitudes towards epilepsy contribute to the manifestation of discrimination against individuals with the condition [8]. The stigma associated with epilepsy impacts negatively on the quality of life of the sufferers [1] [9] [10]. However, the extent and the manifestations of stigma vary from one locality to another as well as with clinical contexts and social status of the individual [2] [11] [12].

Some of the consequences of having a stigmatized identity for individuals with epilepsy include high rates of anxiety, depression and decreased life satisfaction [2]. Other consequences include emotional reactions like guilt, shame and feeling of embarrassment, and diminished social interactions [13]. The prevalence of stigmatization among persons with epilepsy is about $50 \%$ in the developed countries [1] [14]. To cope with this prejudice and social rejection, individuals with epilepsy tend to maintain secrecy about their condition, and rarely make reference to it in the course of social interactions [15].

The understanding of stigmatization in epilepsy and its correlates is relevant to the management of the condition in Africa [16]. Stigma researchers have 
generally characterized stigma as either felt or enacted [11] [12]. Enacted stigma manifests as discrimination against the stigmatized person imposed by others, whereas felt stigma is the fear of enacted stigma experienced by the stigmatized person [10]. Felt stigma may result in the stigmatized person intentionally avoiding contact with others in an attempt to avoid enacted stigma [17]. The nature and degree of stigma are influenced by the clinical course, drug side effects, age, gender, education and employment status, among other factors [2] [11] [18] [19].

The epilepsy treatment gap in Sub-Saharan Africa results from several factors, including belief systems that attribute epilepsy to supernatural rather than medical causes, paucity of healthcare infrastructure, inadequate trained health personnel and the direct and indirect cost of epilepsy care [13] [20]. The existence of this high treatment gap leads to high rates of seizure-related complications and injuries [21] [22]. The poverty and social exclusion that result from epilepsy contributes to the reduced accessibility of epilepsy treatment in Africa [13]. The resulting worsening of the epilepsy treatment gap leads to unpredictable seizures with attendant potential to cause harm through injuries, severe burns, drowning, or fractures [23] [24].

The enactment of stigma against individuals with epilepsy is poignantly felt in the context of employment [11] and schooling [25] [26]. Epilepsy limits employment opportunities due to safety and health considerations or fears of associating with a stigmatized individual. Not much is known about the experience of stigmatization and its consequences among epileptic individuals receiving treatment in southeast Nigeria.

In the African setting, burns is considered as the quintessential stigmata of chronic epilepsy [13] and therefore perceived as a clue for labeling and stigmatization [27]. It has been observed that the major drivers of stigma are under-resourced medical services, inadequate control of seizures and widespread misconception and poor knowledge regarding epilepsy [28]. Stigmatization of individuals with epilepsy is undergirded by widespread misconception that the condition is a contagious disease spread by body fluids of convulsing patients [29] and imputed causal role of witchcraft and sorcery [27] as well as the angst and retribution from offended gods and ancestors [13]. All of these false explanatory models negatively impact on epilepsy stigma and require intervention to improve the social outcome of the disease in Africa.

The major aim of this study was to determine the frequency of experience of stigmatization and its correlates among individuals attending a tertiary facility that provides treatment for epilepsy and other neurological conditions in south-east Nigeria.

\section{Methodology}

\subsection{Design}

This was a cross-sectional descriptive study conducted among individuals receiving 
treatment for epilepsy in a tertiary referral specialist hospital. The study was conducted between April and September 2016.

\subsection{Setting}

This study was carried out at the outpatient neurology service of the University of Nigeria Teaching Hospital, Ituku Ozalla, a foremost tertiary referral and teaching centre for individuals with epilepsy and other neurological disorders.

\subsection{Participants \& Sampling}

The participants for this study were individuals who were receiving treatment for epilepsy and met the following inclusion criteria: 1) Being free from co-morbid physical illnesses like diabetes, hypertension, HIV/AIDS, cardiac, renal or related systemic diseases; 2) Being free from major psychiatric disorders or learning disability; 3) Maintaining a regular clinic attendance over the preceding six months; 4) Being on regular anti-epileptic drug regimen and 5) Gave consent to participate in the study. All patients with pseudoseizures and recently diagnosed epilepsy were excluded from the study.

The sample consisted of consecutively presenting patients who attended the clinic for their epilepsy treatment. Individuals who were considered potential candidates for study recruitment were requested to participate after due explanation about the study had been given. All consenting persons were interviewed in a private room using the study questionnaires.

\subsection{Data Collection}

The participants who met the outlined inclusion criteria were interviewed with a semi-structured questionnaire, specifically designed by the investigators after a review of the relevant literature. The questionnaire sought to elicit data on sociodemographic variables (sex, age, marital status and education), seizure-related variables (age of onset of seizures, duration of epilepsy and recent seizure frequency). The data on the seizure type was extracted from the patients' charts. In addition, data pertinent to the evaluation of stigma experience was also collected. In this regard, the scale for collection of stigma data designed for European studies [30] was utilised for the collection of data on perceived stigma whereas data on enacted stigma was elicited using the investigators' purposedesigned instrument. The perceived stigma scale consists of three items that pertain to the perception of individuals with epilepsy by other people with whom they interact. It had been found to be very suitable for use in European populations. On the other hand, the design of the questionnaire items in the enacted stigma scale was guided by the empirical literature on epilepsy in developing countries. The scoring for each form of stigma (perceived or enacted) was dichotomous, with individuals answering "yes" or "no" to each of the component items. The categorization of participants according to the stigma experience status for each form of stigma was based on the aggregation of persons that 
scored yes to at least one of the items on either of the stigma measuring instruments. The questionnaire was translated into Igbo language by an expert in University of Nigeria, Nsukka and back translated to English by a bilingual specialist in a radio broadcasting station in our city. The Igbo version of the questionnaire was used to Interview all participants who could not understand English.

\subsection{Ethical Considerations}

The study was conducted after ethical clearance had been obtained from the Hospital Ethical Committee. Also prospective participants were informed that they would not suffer any adverse care effects if they chose not to participate in the study and also that if they chose to participate, their responses would be treated with the utmost of confidentiality and anonymity.

\subsection{Data Analysis}

The collected data were analyzed using SPSS version 15, after due data cleaning. The outcomes of the analyses were expressed as frequencies, rates, and percentages duely presented in tables. The mean and median were the principal measures of central tendency explored in the study. The bivariate relationships between variables were explored using the chi squared test for comparison of proportions, and analysis of variance (ANOVA) for comparing the differences in means. The level of statistical significance for all analyses was set at $\mathrm{p}<.05$.

\section{Results}

\subsection{Characteristics of the Sample}

The participants consisted of 93 patients, $57.0 \%$ of whom were males. The participants had a mean age of $30.2 \pm 10.3$ years and a range of $14-67$ years. The male participants were slightly older than the females (mean of $30.9 \pm 10.8$ years versus $29.4 \pm 9.6$ years $(p=0.483)$. Over two-thirds of the participants, 65 (69.9\%) were single whereas 17 (18.3\%) were married. There were slightly more urban than rural dwellers among the participants 48 (51.6\%) versus 45 (48.4\%). More than half of the participants, 53 (57.0\%) had secondary school education, whereas 31 (33.3\%) had primary school education or none. The details of the sample socio-demographic characteristics are provided in Table 1.

The majority of the participants $(74.3 \%)$ were characterized as having generalized tonic-clonic seizures, $16.1 \%$ had partial seizures and $9.6 \%$ had partial seizures with generalization. The mean duration of suffering epilepsy among the participants was $11.1 \pm 9.7$ years with a range of $1-39$ years whereas the mean age of onset for the seizures was $26.9 \pm 5.0$ years. Table 2 provides details of the seizure-related characteristics of the participants. Most of the participants (74.2\%) had had not more than five seizures in the preceding six months whereas a minority (7.5\%) had had more than ten seizure episodes within the preceding six months. 
Table 1. Socio-demographic characteristics of the study participants.

\begin{tabular}{|c|c|c|}
\hline Characteristic & Number $(\mathrm{N}=93)$ & Percent (\%) \\
\hline \multicolumn{3}{|l|}{ Sex } \\
\hline Male & 53 & 57.0 \\
\hline Female & 40 & 43.0 \\
\hline \multicolumn{3}{|l|}{ Age (Years) } \\
\hline Mean & 30.2 & \\
\hline Standard Deviation & 10.3 & \\
\hline Median & 29.0 & \\
\hline Range & $14-67$ & \\
\hline \multicolumn{3}{|l|}{ Marital Status } \\
\hline Single & 65 & 69.9 \\
\hline Married & 17 & 18.3 \\
\hline Separated, divorced or Widowed & 11 & 11.8 \\
\hline \multicolumn{3}{|l|}{ Place of Residence } \\
\hline Rural & 45 & 48.4 \\
\hline Urban & 48 & 51.6 \\
\hline \multicolumn{3}{|l|}{ Education } \\
\hline Primary school Education or None & 31 & 33.3 \\
\hline Secondary school Education & 53 & 57.0 \\
\hline Tertiary Level Education & 9 & 9.7 \\
\hline
\end{tabular}

Table 2. Seizure-related characteristics of the study participants.

\begin{tabular}{lcc}
\hline \multicolumn{1}{c}{ Seizure-related Variable } & Number $(\mathrm{N}=93)$ & Percent (\%) \\
\hline Seizure type & 15 & 16.1 \\
Partial seizures & 9 & 9.6 \\
Partial seizure with secondary generalization & 69 & 74.3 \\
Generalized tonic-clonic seizures & & \\
Seizure duration (Years) & 11.1 & \\
Mean & 9.7 & \\
Standard Deviation & $1-39$ & \\
Range & & \\
Age of onset of Seizures (Years) & 26.9 & \\
Mean & 5.0 & \\
Standard deviation & $7-62$ & 74.2 \\
Range & & 18.3 \\
Seizure Frequency in the past Six Months & 69 & 7.5 \\
$\leq 5$ & 17 & \\
6 - 10 & 7 & \\
$>10$ & & \\
\hline
\end{tabular}




\subsection{The Experience of Stigma}

Of the 93 participants, $43(46.2 \%)$ reported having experienced perceived stigma. Nineteen participants $(20.4 \%)$ stated that they had had the experience of being avoided by other people, $16.1 \%$ (15 out of 93 ) had felt that other people were uncomfortable with them whilst $9.7 \%$ felt that people looked down on them on account of suffering epilepsy. The details of the responses are displayed in Table 3.

In a similar vein, $67.7 \%$ (63 out of 93) had experienced enacted stigma in the course of living with epilepsy. Forty out of 93 (43.0\%) reported that they had experienced being told they were possessed, $34.4 \%$ affirmed they had been avoided by other people whilst $33.3 \%$ stated that they had experienced being told they were witches. Table 4 depicts the experience of enacted stigma among the participants. Twelve of the participants (12.9\%) reported that they had been treated badly by their family members whereas $3.2 \%$ stated that health care providers had treated them badly on account of suffering epilepsy.

Related to this, $34.4 \%$ of the participants admitted they had suffered burns or other severe bodily injury from epilepsy, $32.3 \%$ affirmed that they experienced restriction or special protection from their family members and $23.7 \%$ stated that individuals outside their close family knew about their epileptic condition. A higher proportion of the participants who had suffered burns or related injuries reported experiencing perceived stigma $(65.6 \%$ versus $36.1 \%, p<0.05)$ as well as enacted stigma ( $81.3 \%$ versus $60.7 \% ; p<0.05$ ), in comparison with individuals who had not endorsed these experiences. Similarly, $77.3 \%$ of the individuals whose epileptic condition were known to people outside their family had experienced perceived stigma, whereas only the $36.6 \%$ of the persons who felt stigmatized even though their seizures were not known to people who were not their close relatives $(p<0.05)$. A similar observation was made in relation to enacted stigma $(81.8 \%$ versus $63.4 \%$; $p<0.05)$. Also, among individuals who felt they were being restricted and given extra protection by their families, a higher proportion reported experiencing perceived stigma than those who were not (70.0\% versus $34.9 \% ; p<0.05)$. This was also the case in relation to enacted stigma $(83.3 \%$ versus $60.3 \% ; p<0.05)$.

Table 3. The experience of perceived stigma among 93 patients in South-east Nigeria.

\begin{tabular}{|c|c|c|c|c|}
\hline \multirow{3}{*}{ Component Items } & \multicolumn{4}{|c|}{ Experience of Perceived Stigma } \\
\hline & \multicolumn{2}{|c|}{ YES } & \multicolumn{2}{|c|}{$\mathrm{NO}$} \\
\hline & Number & Percent & Number & Percent \\
\hline \multicolumn{5}{|l|}{ Have you ever felt that on account of epilepsy: } \\
\hline 1) Some people are uncomfortable with you & 15 & $16.1 \%$ & 78 & $83.9 \%$ \\
\hline $\begin{array}{l}\text { 2) Some people look down on you and } \\
\text { treat you like an inferior person }\end{array}$ & 9 & $9.7 \%$ & 84 & $90.3 \%$ \\
\hline 3) Some people avoid you & 19 & $20.4 \%$ & 74 & $79.6 \%$ \\
\hline Total experience of perceived stigma & 43 & $46.2 \%$ & 50 & $53.8 \%$ \\
\hline
\end{tabular}

${ }^{\ddagger}$ Derived from Scale for Epilepsy Stigma [30]. 
Table 4. The experience of enacted stigma and stigma promoting factors among 93 patients in South-east Nigeria.

\begin{tabular}{|c|c|c|c|c|}
\hline \multirow{3}{*}{ Component Items } & \multicolumn{4}{|c|}{ Experience of Enacted Stigma } \\
\hline & \multicolumn{2}{|c|}{ YES } & \multicolumn{2}{|c|}{ NO } \\
\hline & Number & Percent & Number & Percent \\
\hline \multicolumn{5}{|l|}{ Have you ever experienced any of the following: } \\
\hline 1) Have you ever been told that you are possessed? & 40 & $43.0 \%$ & 53 & $57.0 \%$ \\
\hline 2) Have you ever been told that you are a witch? & 31 & $33.3 \%$ & 62 & $66.7 \%$ \\
\hline 3) Have you ever been told you will never marry? & 12 & $12.9 \%$ & 81 & $87.1 \%$ \\
\hline 4) Have you ever been told you will never get a good job? & 14 & $15.1 \%$ & 79 & $84.9 \%$ \\
\hline $\begin{array}{l}\text { 5) Have you ever been told that you will } \\
\text { never be able to keep a job? }\end{array}$ & 14 & $15.1 \%$ & 79 & $84.9 \%$ \\
\hline $\begin{array}{l}\text { 6) Have you ever been told that you } \\
\text { should never play or interact with others? }\end{array}$ & 23 & $24.7 \%$ & 70 & $75.3 \%$ \\
\hline 7) Have you ever been avoided by other people? & 32 & $34.4 \%$ & 61 & $65.6 \%$ \\
\hline $\begin{array}{l}\text { 8) Have you ever been treated badly by } \\
\text { healthcare workers? }\end{array}$ & 3 & $3.2 \%$ & 90 & $96.8 \%$ \\
\hline $\begin{array}{l}\text { 9) Have you ever been treated badly by } \\
\text { your family members? }\end{array}$ & 12 & $12.9 \%$ & 81 & $87.1 \%$ \\
\hline Total enacted stigma experience $^{\dagger}$ & 63 & $67.7 \%$ & 30 & $32.3 \%$ \\
\hline \multirow{3}{*}{ Stigma promoting factors } & \multicolumn{4}{|c|}{ Presence of stigma promoting factor } \\
\hline & \multicolumn{2}{|c|}{ YES } & \multicolumn{2}{|c|}{ NO } \\
\hline & Number & Percent & Number & Percent \\
\hline $\begin{array}{l}\text { Have you ever sustained burns or any } \\
\text { other severe injury on account of your condition? }\end{array}$ & 32 & $34.4 \%$ & 61 & $65.6 \%$ \\
\hline $\begin{array}{l}\text { Do you receive extra protection or } \\
\text { restrictions from your family members? }\end{array}$ & 30 & $32.3 \%$ & 63 & $67.7 \%$ \\
\hline $\begin{array}{l}\text { Do people outside your close } \\
\text { family know about your condition? }\end{array}$ & 22 & $23.7 \%$ & 71 & $76.3 \%$ \\
\hline
\end{tabular}

${ }^{\dagger}$ Many respondents endorsed more than one form of enacted stigma.

\subsection{Correlates of Stigma Experience}

The experience of perceived stigma was higher among females (52.5\%) relative to males $(41.5 \%)$. The observed difference was however not statistically significant $(p=0.293)$. The experience of perceived stigma was higher among individuals aged 30 - 40 years (50.0\%) relative to those aged $\leq 29$ years $(44.7 \%)$ and $\geq 45$ years $(40.0 \%)$ respectively. However, this observed difference was not statistically significant $(p>0.05)$. Similarly, individuals who were currently single (single, divorced, separated, or widowed) reported experiencing perceived stigma more than currently married individuals (48.7\% versus $35.3 \%)$. However, this difference did not attain statistical significance $(p>0.05)$. The relationship between the socio-demographic variables and the experience of stigma is depicted in Table 5. 
Table 5. Relationship between selected socio-demographic variables and the experience of stigma.

\begin{tabular}{|c|c|c|c|c|c|c|}
\hline \multirow{3}{*}{ Demographic variables } & \multicolumn{6}{|c|}{ Perceived Stigma } \\
\hline & \multicolumn{2}{|c|}{ YES } & \multicolumn{2}{|c|}{ NO } & \multicolumn{2}{|c|}{ Analysis } \\
\hline & $\mathrm{N}$ & $\%$ & $\mathrm{~N}$ & $\%$ & $X^{2}$ & $P_{\text {value }}$ \\
\hline \multicolumn{7}{|l|}{ Sex } \\
\hline Male & 22 & $41.5 \%$ & 31 & $58.5 \%$ & & \\
\hline Female & 21 & $52.5 \%$ & 19 & $47.5 \%$ & 1.11 & 0.293 \\
\hline \multicolumn{7}{|l|}{ Age (Years) } \\
\hline$\leq 29$ & 21 & $44.7 \%$ & 26 & $55.3 \%$ & & \\
\hline $30-44$ & 18 & $50.0 \%$ & 18 & $50.0 \%$ & .41 & $>0.05$ \\
\hline$\geq 45$ & 4 & $40.0 \%$ & 6 & $60.0 \%$ & & \\
\hline \multicolumn{7}{|l|}{ Marital Status } \\
\hline Currently Single & 37 & $48.7 \%$ & 39 & $51.3 \%$ & 1.00 & $>0.05$ \\
\hline Currently Married & 6 & $35.3 \%$ & 11 & $64.7 \%$ & & \\
\hline \multicolumn{7}{|l|}{ Place of Residence } \\
\hline Urban & 15 & $31.3 \%$ & 33 & $68.7 \%$ & 8.96 & 0.003 \\
\hline Rural & 28 & $62.2 \%$ & 17 & $37.8 \%$ & & \\
\hline \multicolumn{7}{|l|}{ Education } \\
\hline None or primary & 21 & $67.7 \%$ & 10 & $32.3 \%$ & 8.66 & 0.005 \\
\hline \multirow[t]{2}{*}{ Secondary or higher } & 22 & $35.5 \%$ & 40 & $64.5 \%$ & & \\
\hline & \multicolumn{6}{|c|}{ Enacted Stigma } \\
\hline \multicolumn{7}{|l|}{ Sex } \\
\hline Male & 33 & $62.3 \%$ & 20 & $37.7 \%$ & & \\
\hline Female & 30 & $75.0 \%$ & 10 & $25.0 \%$ & 1.69 & 0.193 \\
\hline \multicolumn{7}{|l|}{ Age (Years) } \\
\hline$\leq 29$ & 16 & $34.0 \%$ & 31 & $66.0 \%$ & & \\
\hline $30-44$ & 6 & $16.7 \%$ & 30 & $83.3 \%$ & & \\
\hline$\geq 45$ & 8 & $80.0 \%$ & 2 & $20.0 \%$ & 14.22 & 0.001 \\
\hline \multicolumn{7}{|l|}{ Marital Status } \\
\hline Currently Single & 56 & $73.7 \%$ & 20 & $26.3 \%$ & & \\
\hline Currently Married & 7 & $41.2 \%$ & 10 & $58.8 \%$ & 6.72 & $<0.01$ \\
\hline \multicolumn{7}{|l|}{ Place of Residence } \\
\hline Urban & 28 & $58.3 \%$ & 20 & $41.7 \%$ & & \\
\hline Rural & 35 & $77.8 \%$ & 10 & $22.2 \%$ & 4.02 & 0.045 \\
\hline \multicolumn{7}{|l|}{ Education } \\
\hline None or primary & 24 & $77.4 \%$ & 7 & $22.6 \%$ & & \\
\hline Secondary or higher & 39 & $62.9 \%$ & 23 & $37.1 \%$ & 1.99 & $>0.05$ \\
\hline
\end{tabular}


The experience of perceived stigma was higher among rural residents relative to urban dwellers $(62.2 \%$ versus $31.3 \%)$. The observed difference was strongly statistically significant $(p<0.01)$. Similarly the experience of perceived stigma was higher among individuals with little or no education (67.7\%) relative to individuals who had attended secondary schools or higher institutions (35.5\%). The observed difference was strongly statistically significant $(p<0.01)$.

With regard to duration of seizures and the experience of perceived stigma, the highest level of perceived stigma (61.8\%) was observed among individuals who had suffered the condition for longer than 10 years whereas the lowest level (27.8\%) was observed among individuals who had suffered the condition for 5 years or less. Persons that had suffered the condition for $6-10$ years had an intermediate level of stigma experience $(52.2 \%)$. These differences were statistically significant $(p<0.01)$. Table 6 provides details of the relationship between the seizure-related variables and the experience of stigma.

Table 6. Relationship between selected seizure-related variables and the experience of stigma.

\begin{tabular}{|c|c|c|c|c|c|c|}
\hline \multirow{3}{*}{ Seizure-related Variables } & \multicolumn{6}{|c|}{ Perceived Stigma } \\
\hline & \multicolumn{2}{|c|}{$\mathrm{NO}$} & \multicolumn{2}{|c|}{ YES } & \multicolumn{2}{|c|}{ Analysis } \\
\hline & $\mathrm{N}$ & $\%$ & $\mathrm{~N}$ & $\%$ & $X^{2}$ & $P$ Value \\
\hline \multicolumn{7}{|c|}{ Duration of Suffering Epilepsy (Years) } \\
\hline$\leq 5$ & 10 & $27.8 \%$ & 26 & $72.2 \%$ & & \\
\hline $6-10$ & 12 & $52.2 \%$ & 11 & $47.8 \%$ & 7.99 & \\
\hline$>10$ & 21 & $61.8 \%$ & 13 & $38.2 \%$ & & $<0.05$ \\
\hline \multicolumn{7}{|c|}{ Seizure Frequency in the past 6 months } \\
\hline$\leq 5$ & 27 & $39.1 \%$ & 42 & 60.9 & & \\
\hline$\geq 6$ & 16 & $66.7 \%$ & 8 & $33.3 \%$ & 5.46 & $<0.05$ \\
\hline \multicolumn{7}{|l|}{ Age of Onset of Seizures } \\
\hline$<20$ years & 17 & $38.6 \%$ & 27 & $61.4 \%$ & & \\
\hline \multirow[t]{2}{*}{$\geq 20$ years } & 26 & $53.1 \%$ & 23 & $46.9 \%$ & 1.94 & $>0.05$ \\
\hline & \multicolumn{6}{|c|}{ Enacted Stigma } \\
\hline \multicolumn{7}{|c|}{ Duration of Suffering Epilepsy (Years) } \\
\hline$\leq 5$ & 19 & $52.8 \%$ & 17 & $47.2 \%$ & & \\
\hline $6-10$ & 17 & $73.9 \%$ & 6 & $26.1 \%$ & & \\
\hline$>10$ & 27 & $79.4 \%$ & 7 & $20.6 \%$ & 6.21 & $<0.05$ \\
\hline \multicolumn{7}{|c|}{ Seizure Frequency in the past 6 months } \\
\hline$\leq 5$ & 46 & $66.7 \%$ & 23 & $33.3 \%$ & & \\
\hline$\geq 6$ & 17 & $70.8 \%$ & 7 & $29.2 \%$ & 0.14 & $>0.05$ \\
\hline \multicolumn{7}{|l|}{ Age of Onset of Seizures } \\
\hline$<20$ years & 36 & $81.8 \%$ & 8 & $18.2 \%$ & & \\
\hline$\geq 20$ years & 27 & $55.1 \%$ & 22 & $44.9 \%$ & 7.57 & $<0.01$ \\
\hline
\end{tabular}


Regarding the seizure frequency in the preceding 6 months, individuals who had 6 or more seizures were more likely to report perceived stigma (66.7\%) than individuals who had 5 seizures or less (39.1\%). The observed difference was statistically significant $(p<0.05)$. Also, individuals whose onset of epilepsy started after the age of $20 \mathrm{yrs}$ were more likely to report experiencing perceived stigma (53.1\%) than individuals whose onset of epilepsy occurred before the age of 20 yrs (38.6\%). However, the observed difference was not statically significant ( $p>$ $0.05)$.

There was a higher rate of reporting of enacted stigma among females relative to males $(75.0 \%$ versus $62.3 \%)$. However, this difference did not attain statistical significance. Individuals who were currently single reported experiencing enacted stigma more frequently than those who were currently married $(73.7 \%$ versus $41.2 \%$ ). The observed difference was strongly statistically significant ( $p<$ $0.01)$. The experience of enacted stigma was highest among older individuals ( $\geq 45$ years) $(80.0 \%)$ and lowest among persons aged 30 - 40 years $(16.7 \%)$ whereas the youngest age group ( $\leq 29$ years) had a rate that was intermediate (34.0\%). This difference was strongly statistically significant $(p=0.001)$.

There was a higher frequency of reporting of enacted stigma among rural residents relative to urban dwellers (77.8\% versus $58.3 \%)$. The difference in rates was statistically significant $(p<0.05)$. Similarly, there was a higher rate of reporting of enacted stigma among individuals with little or no education relative to those who attained higher levels of education (secondary school or higher) (77.4\% versus $62.9 \%)$. However this observed difference did not attain statistical significance $(p>0.05)$.

The report of experiencing enacted stigma was related to the duration of suffering the condition. Of the individuals who had suffered epilepsy for ten years or longer, $79.4 \%$ reported having experienced enacted stigma, $73.9 \%$ of the individuals who had suffered the condition for 6 - 10 years affirmed having the experience, whereas individuals who had suffered the condition for 5 years or less, were the least likely to report having experienced enacted stigma $(52.8 \%)$. The observed differences were strongly statistically significant $(p<0.01)$.

There was a relatively higher level of reporting of enacted stigma among individuals that had a higher seizure frequency $(70.8 \%)$ relative to the group that had five or fewer seizures in the preceding six months (66.7\%). However, this difference did not attain statistical significance $(p>0.05)$. The experience of enacted stigma was much higher among individuals whose seizures started before the age of 20 years $(81.8 \%)$ relative to the group whose seizures began after the age of 20 years $(55.1 \%)$. The observed difference was strongly statistically significant $(p<$ $0.01)$.

Finally, $65.6 \%$ of individuals who had suffered burns or other severe injury reported experiencing perceived stigma whereas only $36.1 \%$ had perceived stigma among persons who had not suffered such injuries. The observed difference was statistically significant $(p<0.01)$. Similarly, $77.3 \%$ of individuals who stated 
that their suffering epileptic seizures were known to persons outside their families reported experiencing perceived stigma. This is in contrast to the $36.6 \%$ rate of experience perceived stigma among individuals who felt that their seizures were not known to people outside their families. The observed difference was statistically significant $(p<0.001)$. Table 7 shows the interaction between the seizure promoting factors and the experience of stigma. Related to this, $70.0 \%$ of individuals who stated that they were being given extra protection or restrictions by their families had experienced perceived stigma, in comparison with the $34.9 \%$ rate of experience of perceived stigma among individuals who had not received such extra protection. This observed difference was strongly statistically significant.

With regard to enacted stigma, $81.3 \%$ of persons who had experienced burns or other sever injury from epilepsy reported suffering enacted stigma, whereas only $60.7 \%$ of those who had not suffered burns or such an injury had experienced enacted stigma. The observed difference was statistically significant $(p<$ $0.05)$. Also, among individuals who stated that their epileptic condition was

Table 7. Relationship between seizure promoting factors and the experience of stigma.

\begin{tabular}{|c|c|c|c|c|c|c|}
\hline \multirow{3}{*}{ Seizure-promoting factors } & \multicolumn{6}{|c|}{ Presence of Seizure Promoting Factor } \\
\hline & \multicolumn{2}{|c|}{ YES } & \multicolumn{2}{|c|}{ NO } & \multicolumn{2}{|c|}{ Analysis } \\
\hline & $\mathrm{N}$ & $\%$ & $\mathrm{~N}$ & $\%$ & $X^{2}$ & $P$ value \\
\hline \multicolumn{7}{|l|}{ Experienced burns or severe injury } \\
\hline Yes & 21 & 65.6 & 11 & 34.4 & & \\
\hline No & 22 & 36.1 & 39 & 63.9 & 7.38 & $<0.01$ \\
\hline \multicolumn{7}{|c|}{ Awareness of the condition to outsiders } \\
\hline Yes & 17 & 77.3 & 5 & 22.7 & 11.17 & $<0.001$ \\
\hline No & 26 & 36.6 & 45 & 63.4 & & \\
\hline \multicolumn{7}{|l|}{ Given extra protection or restrictions } \\
\hline Yes & 21 & 70.0 & 9 & 30.0 & 10.06 & $<0.001$ \\
\hline \multirow[t]{2}{*}{ No } & 22 & 34.9 & 41 & 65.1 & & \\
\hline & \multicolumn{6}{|c|}{ Enacted Stigma } \\
\hline \multicolumn{7}{|l|}{ Experienced burns or severe injury } \\
\hline Yes & 26 & 81.3 & 6 & 18.7 & & \\
\hline No & 37 & 60.7 & 24 & 39.3 & 4.77 & $<0.05$ \\
\hline \multicolumn{7}{|c|}{ Awareness of the condition to outsiders } \\
\hline Yes & 18 & 81.8 & 4 & 18.2 & 2.61 & $>0.05$ \\
\hline No & 45 & 88.2 & 6 & 11.8 & & \\
\hline \multicolumn{7}{|l|}{ Given extra protection or restrictions } \\
\hline Yes & 25 & 83.3 & 5 & 16.7 & 4.93 & $<0.05$ \\
\hline No & 38 & 60.3 & 25 & 39.7 & & \\
\hline
\end{tabular}


known to individuals outside their families, $81.8 \%$ had experienced enacted stigma, in comparison with the $88.2 \%$ rate among those whose epileptic conditions were not known to persons outside their families. The observed difference was however not statistically significant $(p>0.05)$. Related to this, $83.3 \%$ of the individuals who stated that they had been receiving extra protection or restrictions from their families reported experiencing enacted stigma, in contrast to the $60.3 \%$ rate observed among individuals who had not affirmed receiving this kind of protection or restrictions from their families. The observed difference in rates was statistically significant $(p<0.05)$.

\section{Discussion}

The results of this study show that social stigma is a major concern among the epileptic patients that are being treated in south-east Nigeria. The findings showed that $46.2 \%$ and $67.7 \%$ of the participants had experienced perceived and enacted stigma respectively. This is similar to the findings of studies in the developing countries [31] [32] [33]. The subtle differences in exact estimates may be related to the type of instruments utilised for stigma assessment and the differences in the study settings. Even in the developed countries, concerns about stigma influence the quality of life of the patients and their uptake of the available treatment services [1] [14] [34]. Stigma is a common feature of living with epilepsy in Africa [13] [21] [31] and the experience is related to the causal beliefs the people hold. Stigma has the consequence of making afflicted persons fear being rejected or avoided by other people.

Having inadequate information about epilepsy is one of the major drivers and perpetuating factors for epilepsy stigma [28] [35] [36]. To this is added the effect of misconceptions, stereotypes and emotional responses to epilepsy in different cultures and geographical settings [37]. Research studies have demonstrated the perversity of stigmatization and discrimination against the epileptic and mentally ill around the world [38]. All persons in the social network of these individuals are involved in this stigmatisation process [39] [40] [41]. Individuals with stigmatising conditions are believed to internalise the devaluing messages they receive from the people around them, and anticipate rejection during interactions. In addition, these individuals develop coping strategies like keeping their conditions secret or withdrawing from social interaction altogether [42] [43] in order to prevent the anticipated rejection. This has been observed among mentally ill persons and among individuals with epilepsy. Such individuals limit their interactions either to similarly stigmatised persons or family members who already know about their conditions and are accepting of them despite the negative attribution [43]. The stigma of epilepsy is often linked to emotional distress, social isolation and withdrawal, lowered self-esteem, problems with employment and interpersonal relationships [1] [44].

A number of misconceptions and wrong causal attribution attend the experience of epilepsy in Nigeria. The consequence of this is that epilepsy is greatly 
feared and misunderstood [4]. This is reflected in the individual items that were endorsed by the participants who had experienced various forms of enacted stigma. The experience of enacted stigma is undergirded by the societal construal of the disease as contagious and the negative effects of this perception on the self-image and confidence of the affected persons [45]. Over one-third of the participants had been told that they were possessed by evil spirits or witchcraft or had been avoided by other people on account of these considerations. People in Africa fear contact with epilepsy because they believe that seizures can be contracted if contact is made with saliva, urine, faeces or flatus expelled during a convulsion [29] [46]. This fear of contagion leads to avoidance of convulsing persons, social rejection, and unwillingness to intervene during a seizure, with higher risk of attendant morbidity like burns [47], supernatural attribution of seizures [27] with resultant traditional help-seeking, which in turn, leads to delayed medical help-seeking, sustaining the epilepsy treatment gap, chronicity and untoward morbidity \& disability [48]. Dealing with stigma exerts gross negative effects on the lives of epileptic patients and contributes to their social isolation, unemployment and lack of interest in seeking medical treatment [30] [49].

The implication of these is that efforts need to be made to improve the understanding about epilepsy among the general public in order to improve the quality of life of the sufferers and their social acceptance. The negative social perception of epileptic individuals limits their access to social resources and capital [29] [34] [50]. Working towards improved treatment accessibility for epileptic patients should be coupled with efforts directed toward public education about the condition [21] [31] [51].

Our results showed that the reports of perceived and enacted stigma were disproportionately more likely to arise from females than males. The reports of previous research projects showed that there appear to be divergent findings in respect of the relationship between gender and the experience of stigma. Whereas some studies showed the absence of statistically significant gender differences in the experience of stigma [32] [52] [53], some others showed a female preponderance of feeling stigmatized [54] [55]. On the other hand, an Ethiopian study reported a male preponderance in the experience of stigma [31]. Perhaps the social impact of epilepsy may exert more negative effects on women because of their lower social status, lower levels of education, and not having adequate skills for employment or independent living. There is clearly a need for more focused studies to clarify the influence of gender on the experience of epilepsy related stigma in our setting.

In this study, the feeling of stigmatisation was also greater among individuals who were currently single (single, divorced, separated, or widowed) relative to married persons. This may be related to the fact that the salience of seizure experience and the fear of rejection were more intensely felt by individuals that have need for intimate partners compared with individuals in more stable relationships. This feeling of stigmatisation is more intensely felt in circumstances where the concealment of the epilepsy history and the fear of detection co-exist, a situation 
that is more poignant in intimate relationships. This view is supported by the findings of a study conducted in India which showed that the majority of the epileptic women surveyed had concealed the condition from their intending marital partners prior to marriage [55]. Riasi et al. (2015) had drawn attention to the interaction between externalized and internalized stigma of epilepsy in influencing the marital outcomes of women with epilepsy who were currently unmarried [56]. Often, the fear of encountering negative attitudes in the course of close interpersonal interactions makes epileptic patients to restrict their social lives and become reclusive [57].

We did not observe any significant age differences in the experience of perceived stigma. On the other hand, we observed an association between age and enacted stigma. The least level of enacted stigma was reported by individuals aged 45 years and older, whereas younger groups reported higher levels of enacted stigma. Many previous reports had documented higher rates of stigmatization among younger patients [11] [52] [58]. However, there are also discrepant reports. For instance, Shibre et al. (2006) reported higher rates of stigmatization among older patients in Ethiopia [31]. It is noteworthy that their sample consisted of both patients and their relatives, and the latter constituted the bulk of the older persons in their sample. Overall, it looks like older individuals bother less about being stigmatised than younger people because over the years of living with the condition, they would have found some mechanisms of adjusting to the disease and the challenges it poses. For younger people who are yet to understand how best to cope with the limitations posed by epilepsy, the experience of being stigmatised remains a constant concern.

Similarly, we found that the reporting of perceived and enacted stigma was more prevalent among rural than urban residents. Previous reports had documented this pattern [48]. This finding may be related to the close knit relationship in the rural setting where every individual and his activities is known to all other people in the setting, including the fact of being epileptic and the manifestations of the disease. This kind of setting may be associated with greater feelings of shame and fear of anticipated rejection [11] [13]. This contrasts with the situation in the urban settings, where the anonymous nature of the interpersonal interactions makes the possibility of selective disclosure of one's stigmatized condition more practicable [59]. Scambler \& Hopkins (1989) described the selective use of avoidance, reticence, and "guarded disclosure" as coping strategies for enacted stigma [15].

The stigma counteracting effect of higher education had been documented in some studies [37]. Our finding of higher levels of stigmatisation among individuals with little education supports this contention. This finding is probably related to the fact that higher levels of education increase access to information, including relevant health information. Since epilepsy stigma is driven by misconceptions and negative attitudes about epilepsy, this is more likely to be an issue for individuals that have limited access to relevant disconfirming information. Related to this, previous studies had demonstrated that educational interventions 
that seek to change negative attitudes about epilepsy can positively influence established attitudes and beliefs about health conditions like epilepsy and lead to improved adaptive behaviour [54]. In addition, disseminating the correct information about epilepsy is one of the most effective strategies for dealing with epilepsy stigma [60].

Among the seizure-related variables explored in this study, we found that the duration of illness was associated with the experience of both perceived and enacted stigma. This is similar to the findings of the phenomenon in other settings [2] [10]. Similarly, earlier age of onset was associated with the experience of enacted stigma but not perceived stigma. It is likely that having an earlier age of onset of the condition increases the chances of exposure to circumstances that engender the experiencing of discrimination and feelings of shame. Earlier studies had documented the effect of early age of onset of epilepsy in fostering stigmatization as well as contributing to the poor social outcomes associated with epilepsy [10] [61] [62]. These effects may be related to the effect of early onset seizures on psychosocial development, maturation and acquisition of cognitive competence [62]. Also, having more frequent seizures in the recent past was associated with the experience of perceived stigma but not enacted stigma. This finding is however different from those of two other African studies [45] [63] which did not report any effect of seizure frequency on the experience of perceived stigma. On the other hand, the fear of having seizures in public places, which is more poignant among individuals suffering more frequent episodes, correlates with greater perception of stigmatization [52]. Euro-American studies have identified seizure frequency as the most consistent driver of epilepsy associated stigma [64] [65] [66]. Severe and persistent seizures are known to be associated with higher levels of stigma perception [6]. These aspects clearly call for the conduct of larger studies, preferably using longitudinal designs to better understand the effect of seizure frequency and severity on the perception of stigma especially among individuals receiving treatment in resource-poor settings like ours.

The contribution of epilepsy-related injuries like burns in promoting stigma in Africa has been previously highlighted through empirical studies [27]. Even in Europe, epilepsy-related injuries are among the most consistent predictors of stigmatization in research studies [67] [68]. This finding has been validated by our study, which showed that the presence of burns, parental restrictive and protective behaviour, and knowledge of an individual's epileptic condition in the community contributed to varying degrees to the experience of both perceived and enacted stigma among the participants. The implication of these is that actions directed at improving epilepsy care and availability of affordable medicines may be relevant to reducing the social impact of the disease and improving the quality of life of the patients.

Some of the limitations of this study are worthy of note. First, the study was focused on individuals that were receiving active treatment for epilepsy in a specialist referral facility. The findings may therefore not be representative of the 
population of all persons suffering epilepsy in the south-east Nigeria. Next, the small size of the study sample probably affected the power of the statistical analyses to detect differences in proportions, and this could have influenced the findings. Also, the assessment of perceived stigma was done with a three-item instrument developed in European populations. It is not clear to what degree the findings would have differed if more complex ethnographically derived instruments had been utilized for stigma measurement. We are also mindful of the effects of recall bias and social desirability response set on the levels of stigma elicited in this study. However, the influence of these factors cannot be completely eliminated in social research studies of this nature.

\section{Conclusion}

Nonetheless, it can be surmised from this study that both perceived and enacted stigma are major concerns among individuals receiving treatment for epilepsy in south-east Nigeria. The experience of enacted stigma is undergirded by the belief that epilepsy is a contagious disease and negatively influences the extent of social participation of the sufferers. Dealing with stigma requires giving greater attention to understanding the perception of the condition by the general public and fashioning appropriate educational interventions to bridge the identified knowledge gap. Having improved accessibility to effective treatment for all sufferers will contribute to better seizure control and possibly improved public acceptance. The design of more focused quantitative studies using larger samples will help to validate the findings of this study whereas the conduct of qualitative studies with individual patients will help to deepen the understanding of the lived realities of persons grappling with stigma on a day-to-day basis.

\section{References}

[1] Baker, G.A., Jacoby, A., Buck, D., Staglis, C. and Monnet, D. (1997) Quality of Life of Epilepsy: A European Study. Epilepsia, 38, 353-362. https://doi.org/10.1111/j.1528-1157.1997.tb01128.x

[2] Jacoby, A., Baker, G.A., Steen, N., Potts, P. and Chadwick, D.W. (1996) The Clinical Course of Epilepsy and Its Psychological Correlates: Findings from a UK Community Study. Epilepsia, 37, 148-161. https://doi.org/10.1111/j.1528-1157.1996.tb00006.x

[3] Morell, M.J. (2002) Stigma and Epilepsy. Epilepsy \& Behaviour, 3, S21-S25.

[4] Awaritefe, A. (1989) Epilepsy: The Myth of a Contagious Disease. Culture Medicine \& Psychiatry, 13, 449-456. https://doi.org/10.1007/BF00052051

[5] International League against Epilepsy (2003) The History and Stigma of Epilepsy. Epilepsia, 44, 12-14. https://doi.org/10.1046/j.1528-1157.44.s.6.2.x

[6] McCagh, J. (2014) Quality of Life Issues in Epilepsy. In: Holmes, M.D., Ed., Epilepsy Topics, Intech. https://doi.org/10.5772/58689 https://www.intechopen.com/books/epilepsy-topics/quality-of-life-issues-in-epilepsy

[7] Goffman, E. (1963) Stigma: Notes on the Management of Spoiled Identity. Prentice Hall, New Jersey. 
[8] Fernandes, P.T., Snape, D.A., Beran, R.G. and Jacoby, A. (2011) Epilepsy Stigma: What Do We Know and Where Next? Epilepsy \& Behaviour, 22, 55-62.

[9] Jacoby, A. (2008) Epilepsy and Stigma: An Update and Critical Review. Current Neurology and Neuroscience Reports, 8, 339-344. https://doi.org/10.1007/s11910-008-0052-8

[10] Baker, G.A., Brooks, J., Buck, J.D. and Jacoby, A. (2000) The Stigma of Epilepsy: A European Perspective. Epilepsia, 41, 98-104. https://doi.org/10.1111/j.1528-1157.2000.tb01512.x

[11] Jacoby, A. (1994) Felt versus Enacted Stigma: A Concept Revisited. Evidence from a Study of People with Epilepsy in Remission. Social Science \& Medicine, 38, 269-274.

[12] Jacoby, A. (1992) Epilepsy and Quality of Everyday Life: Findings from a Study of People with Well-Controlled Epilepsy. Social Science and Medicine, 34, 657-666.

[13] Baskind, R. and Birbeck, G.L. (2005) Epilepsy-Associated Stigma in Sub-Saharan Africa: The Social Landscape of a Disease. Epilepsy and Behaviour, 7, 68-73. https://doi.org/10.1016/j.yebeh.2005.04.009

[14] Choi, S.J., Hong, S.B. and Seo, D.W. (2001) Stigma and Quality of Life in Epilepsy. Epilepsia, 41, 98-104.

[15] Scambler, G. and Hopkins, A. (1989) Being Epileptic: Coming to Terms with Stigma. Sociological Health, 8, 26-43. https://doi.org/10.1111/1467-9566.ep11346455

[16] Dilorio, C., Hennessy, M. and Manteuffel, B. (1996) Epilepsy Self-Management: A Test of a Theoretical Model. Nursing Research, 45, 211-217. https://doi.org/10.1097/00006199-199607000-00004

[17] Jacoby, A., Snape, D. and Baker, G.A. (2005) Epilepsy and Social Identity: The Stigma of a Chronic Neurological Disorder. The Lancet Neurology, 4, 171-178.

[18] Birbeck, G.L., Hays, R.D., Cui, X. and Vickrey, B.G. (2002) Seizure Reduction and Quality of Life Improvements in People with Epilepsy. Epilepsia, 43, 535-538. https://doi.org/10.1046/j.1528-1157.2002.32201.x

[19] Reis, R. (2001) Epilepsy and Self-Identity among the Dutch. Medical Anthropology, 19, 355-382. https://doi.org/10.1080/01459740.2001.9966182

[20] Mbuba, C.K., Ngugi, A.K., Newton, C.R. and Carter, J.A. (2008) The Epilepsy Treatment Gap in Developing Countries: A Systematic Review of the Magnitude, Causes, and Intervention Strategies. Epilepsia, 49, 1491-1503. https://doi.org/10.1111/j.1528-1167.2008.01693.x

[21] Jilek-Aall, L., Jilek, M., Kaaya, J., Mkombachepa, L. and Hillary, K. (1997) Psychosocial Study of Epilepsy in Africa. Social Science \& Medicine, 45, 783-795.

[22] Ezeala-Adikaibe, B.A., Achor, J.U., Onwukwe, J. and Agomoh, A. (2012) Seizure Related Injuries among Outpatients in Two Tertiary Hospitals in Southeast Nigeria. Annals of Tropical Medicine and Public Health, 5, 340-343. https://doi.org/10.4103/1755-6783.102047

[23] Newton, C.R. and Garcia, H.H. (2012) Epilepsy in Poor Regions of the World. The Lancet, 380, 1193-1201.

[24] Birbeck, G.L. (2000) Seizures in Rural Zambia. Epilepsia, 41, 277-281. https://doi.org/10.1111/j.1528-1157.2000.tb00156.x

[25] Ojinnaka, N.C. (2002) Teachers' Perception of Epilepsy in Nigeria: A Community Based Study. Seizure, 11, 386-391. https://doi.org/10.1053/seiz.2001.0664

[26] Ibekwe, R.C., Ojinnaka, N.C. and Iloeje, S.O. (2008) Academic Performance of School Children with Epilepsy. West African Journal of Medicine, 27, 74-77. 
[27] Baskind, R.B.G. (2005) Epilepsy Care in Zambia: A Study of Traditional Healers. Epilepsia, 46, 1-6. https://doi.org/10.1111/j.1528-1167.2005.03505.x

[28] Jacoby, A. (2002) Stigma, Epilepsy and Quality of Life. Epilepsy and Behaviour, 3, S10-S20.

[29] Andermann, L. (1995) Epilepsy in Developing Countries. Transcultural Psychiatric Review, 32, 350-384. https://doi.org/10.1177/136346159503200401

[30] Jacoby, A., Baker, G., Smith, D., Dewey, M. and Chadwick, D. (1993) Measuring the Impact of Epilepsy: The Development of a Novel Scale. Epilepsy Research, 16, 83-88.

[31] Shibre, T., Alem, A., Tekle-Haimanot, R., Medhin, G. and Jacobsson, L. (2006) Perception of Stigma in People with Epilepsy and Their Relatives in Butajira, Ethiopia. Ethiopian Journal of Health and Development, 20, 170-176.

[32] Joseph, N., Ray, A., Reshma, B.K., Bhat, S., Herady, M., Kumar, A. and Shri Kiran, K. (2011) Assessment of Quality of Life, Stigma Associated and Self-Management Practices among Patients Suffering from Epileptic Seizures: A Cross Sectional Study. Journal of Neuroscience and Behavioural Health, 3, 91-98.

[33] Rafael, F., Houinato, D., Nubukpo, P., Dubreuil, C.M., Tran, D.S., Odermatt, P., Clement, J.P., Weiss, M.G. and Preux, P.M. (2010) Sociocultural and Psychological Features of Perceived Stigma Reported by People with Epilepsy in Benin. Epilepsia, 51, 1061-1068. https://doi.org/10.1111/j.1528-1167.2009.02511.x

[34] Panter, K. (2004) Is Perceived Stigma Related to Quality of Life in Individuals with Epilepsy? Unpublished MSc Dissertation, University of Bristol.

[35] Fernandes, P.T., Salgado, P.C.B., Noronha, A.L.A., Barbosa, F.D., Souza, E.A.P. and Li, L.M. (2004) Stigma Scale of Epilepsy: Conceptual Issues. Journal of Epilepsy and Clinical Neurophysiology, 10, 213-218.

[36] Fernandes, P.T., Noronha, L.A., Sander, J.W. and Li, L.M. (2008) Stigma Scale of Epilepsy: The Perception of Epilepsy Stigma in Different Cities in Brazil. Arquivos De Neuropsiquaitria, 66, 471-476. https://doi.org/10.1590/S0004-282X2008000400006

[37] Ryan, R., Kempner, K. and Emlen, A.C. (1980) The Stigma of Epilepsy as a Self-Concept. Epilepsia, 21, 433-444. https://doi.org/10.1111/j.1528-1157.1980.tb04091.x

[38] Link, B.G., Phelan, J.C., Bresnahan, M., Stueve, A. and Pescosolido, B.A. (1999) Public Conceptions of Mental Illness: Labels, Causes, Dangerousness and Social Distance. American Journal of Public Health, 89, 1328-1333. https://doi.org/10.2105/AJPH.89.9.1328

[39] Struening, E., Perlick, D., Link, B., Hellman, F., Herman, D. and Sirey, J.A. (2001) The Extent to Which Caregivers Believe Most People Devalue Consumers and Their Families. Psychiatric Services, 52, 1633-1638. https://doi.org/10.1176/appi.ps.52.12.1633

[40] Page, S. (1995) Effects of the Mental Illness Label in 1993: Acceptance and Rejection in the Community. Journal of Health and Social Policy, 7, 61-68. https://doi.org/10.1300/J045v07n02_05

[41] Farina, A., Murray, P.J. and Groh, T. (1978) Sex and Worker Acceptance of a Former Mental Patient. Journal of Consulting and Clinical Psychology, 46, 887-891. https://doi.org/10.1037/0022-006X.46.5.887

[42] Link, B.G., Cullen, F.T., Struening, E., Shrout, P. and Dohrenwend, B.P. (1989) A Modified Labelling Theory Approach in the Area of Mental Disorders: An Empirical Assessment. American Sociology Review, 54, 100-123. https://doi.org/10.2307/2095613 
[43] Link, B., Cullen, F.T., Frank, J. and Wozniak, J. (1987) The Social Rejection of Ex-Mental Patients: Understanding Why Labels Matter. American Journal of Sociology, 92, 1461-1500. https://doi.org/10.1086/228672

[44] Cramer, J.A. (1994) Quality of Life for People with Epilepsy. Neurological Clinics, 12, 1-13.

[45] Taha, M., Balla, S., Hussien, A. and Dafaalla, M. (2014) Stigma of Epilepsy among Patients and Their Relatives Attending Charity Clinic, Omdurman-Sudan, June 2012. Journal of Neurology \& Neurophysiology, 5, 224. https://doi.org/10.4172/2155-9562.1000224

[46] Rwiza, H.T., Matuja, W.B., Kilonzo, G.P., Haule, J., Mbena, P., Mwang’ombola, R. and Jilek-Aall, L. (1993) Knowledge, Attitude, and Practice toward Epilepsy among Rural Tanzanian Residents. Epilepsia, 34, 1017-1023. https://doi.org/10.1111/j.1528-1157.1993.tb02127.x

[47] Carod, F.J. and Vazquez-Cabrera, C. (1998) Magical Thinking and Epilepsy in Traditional Indigenous Medicine. Review of Neurology, 26, 1064-1068.

[48] Birbeck, G. and Kalichi, E. (2003) The Functional Status of People with Epilepsy in Rural Sub-Saharan Africa. Journal of Neurological Sciences, 209, 65-68.

[49] Collings, J. (1990) Psychological Wellbeing and Epilepsy: An Empirical Study. Epilepsia, 31, 418-426. https://doi.org/10.1111/j.1528-1157.1990.tb05497.x

[50] Jilek, W.G. (1979) The Epileptic Outcast Role and Its Background: A Contribution to the Social Psychiatry of Seizure Disorders. Journal of Operational Psychiatry, 10, 128-133.

[51] Martiniuk, A.L.C., Secco, M., Yake, L. and Speechley, K.N. (2010) Evaluating the Effect of a Television Public Service Announcement about Epilepsy. Health Education Research, 25, 1050-1060. https://doi.org/10.1093/her/cyq058

[52] Mbuba, C.K., Abubakar, A., Odermatt, P., Newton, C.R. and Carter, J.A. (2012) Development and Validation of the Kilifi Stigma Scale for Epilepsy in Kenya. Epilepsy \& Behaviour, 24, 81-85.

[53] Ridsdale, L., Morgan, M. and O’Connor, C. (1999) Promoting Self-Care in Epilepsy: The Views of Patients on the Advice They Had Received from Specialists, Family Doctors, and an Epilepsy Nurse. Patient Education and Counseling, 37, 47-57.

[54] Fernandes, P.T., Noronha, A.L., Sander, J.W., Bell, G.S. and Li, L.M. (2007) Training the Trainers and Disseminating Information: A Strategy to Educate Health Professionals on Epilepsy. Arquivos De Neuropsiquaitria, 65, 14-22. https://doi.org/10.1590/S0004-282X2007001000003

[55] Riasi, H., Sanati, A.R. and Ghaemi, K. (2015) The Stigma of Epilepsy and Its Effects on Marital Status. Springer Plus, 3, 762. https://doi.org/10.1186/2193-1801-3-762

[56] Santosh, D., Kumar, T.S., Sarma, P.S. and Radhakrishnan, K. (2007) Women with Onset of Epilepsy Prior to Marriage: Disclose or Conceal? Epilepsia, 48, 1007-1010. https://doi.org/10.1111/j.1528-1167.2007.01040.x

[57] Rhodes, P.J., Small, N.A., Ismail, H. and Wright, J.P. (2007) "What Really Annoys Me Is People Take It like It's a Disability”: Epilepsy, Disability and Identity among People of Pakistani Origin Living in the UK. Ethnicity \& Health, 13, 1-21. https://doi.org/10.1080/13557850701803031

[58] Austin, J.K., MacLeod, J., Dunn, D.W., Shen, J. and Perkins, S.M. (2004) Measuring Stigma in Children with Epilepsy and Their Parents: Instrument Development and Testing. Epilepsy \& Behavior, 5, 472-482. 
[59] Westbrook, L.E., Bauman, L.J. and Shinar, S. (1992) Applying Stigma Theory to Epilepsy: A Test of a Conceptual Model. Journal of Paediatric Psychology, 17, 633-649. https://doi.org/10.1093/jpepsy/17.5.633

[60] Reno, B.A., Fernandes, P.T., Bell, G.S., Sander, J.W. and Li, L.M. (2007) Stigma and Attitudes on Epilepsy: A Study with Secondary School Students. Arquivos De Neuropsiquaitria, 65, 49-54. https://doi.org/10.1590/S0004-282X2007001000008

[61] Agarwal, P., Mehndiratta, M.M., Anthony, A.R., Kumar, N., Dwivedi, R.N., Sharma, P. and Kumar, S. (2006) Epilepsy in India: Nuptiality Behaviour and Fertility. Seizure, 15, 409-415.

[62] Sillanpää, M., Haataja, L. and Shinnar, S. (2004) Perceived Impact of Childhood-Onset Epilepsy on Quality of Life as an Adult. Epilepsia, 45, 971-977. https://doi.org/10.1111/j.0013-9580.2004.44203.x

[63] Atadzhanov, M., Haworth, A., Chomba, E.N., Mbewe, E.K. and Birbeck, G.L. (2010) Epilepsy-Associated Stigma in Zambia: What Factors Predict Greater Felt Stigma in a Highly Stigmatized Population? Epilepsy \& Behaviour, 19, 414-418.

[64] Baker, G.A. (2002) People with Epilepsy: What Do They Know and Understand, and How Does This Contribute to Their Perceived Level of Stigma? Epilepsy \& Behaviour, 3, 26-32.

[65] Smith, G., Ferguson, P.L., Saunders, L.L., Wagner, J.L., Wannamaker, B.B. and Selassie, A.W. (2009) Psychosocial Factors Associated with Stigma in Adults with Epilepsy. Epilepsy \& Behaviour, 16, 484-490.

[66] Moran, N.F., Poole, K., Bell, G., Solomon, J., Kendall, S., McCarthy, M., McCormick, D., Nashef, L., Sander, J. and Shorvon, S.D. (2004) Epilepsy in the United Kingdom: Seizure Frequency and Severity, Antiepileptic Drugs Utilization, and Impact on Life in 1652 People with Epilepsy. Seizure, 13, 425-433.

[67] Buck, D., Baker, G.A., Jacoby, A., Smith, D.F. and Chadwick, D.W. (1997) Patients' Experiences of Injury as a Result of Epilepsy. Epilepsia, 38, 439-444. https://doi.org/10.1111/j.1528-1157.1997.tb01733.x

[68] Baker, G.A., Jacoby, A., Gorry, J., Doughty, J. and Ellina, V., SIGN Group (2005) Quality of Life of People with Epilepsy in Iran, the Gulf, and near East. Epilepsia, 46, 132-140. https://doi.org/10.1111/j.0013-9580.2005.20704.x 